\title{
resenha bibliográfica* book review
}

\author{
José Newton Coelho Meneses $\star \star$ \\ Departamento de História, Faculdade de Filosofia e Ciências Humanas, Universidade Federal de \\ Minas Gerais, Belo Horizonte, Minas Gerais, Brasil
}

MARTINS, Roberto B. Crescendo em silêncio: a incrível economia escravista de Minas Gerais no século XIX. Belo Horizonte: ICAM/ABPHE, 2018, 629p.

Mesmo assim, não é impossível representá-la. Podemos falar dela.

Podemos tentar descrever sua lógica.

Henri Atlan

Os espaços históricos são inexistentes quando a historiografia os ignora. $\mathrm{Ou}$, às vezes ela os torna invisíveis. Ignorar, em alguns casos, é fruto do não acesso a fontes documentais escondidas em acervos dificeis e, em outros, opção fácil de permanência na tradição interpretativa. A história da economia mineira oitocentista foi em certo tempo refratária desses dois tipos de desconhecimento. Mas foi, sobretudo, herdeira de uma compreensão limitada e simplista da economia setecentista: a de que a chamada "decadência da mineração" levou a uma inflexão para uma agricultura de subsistência. É paradoxal como autores de trabalhos de fôlego sobre o setecentos apresentaram uma narrativa de economia agrícola ao mesmo tempo mercantil e de subsistência, tentando colocar

* Submetida: 14 de novembro de 2019; aceita: 23 de novembro de 2019.

$\star \star$ Professor do Departamento de História da Faculdade de Filosofia e Ciências Humanas da Universidade Federal de Minas Gerais. Doutor em História pela Universidade Federal Fluminense.E-mail:jnmeneses@gmail.com 
nessas duas características uma possibilidade histórica de difícil compreensão. Sobre o oitocentos outros tantos inculcavam heranças rigorosas dessa inflexão. A pujança de uma economia interna na longa duração levou tempos para ser apresentada. Sua complexidade, até hoje, exige esforços de pesquisa e de reflexão criativa.

A complicar tal visão simplista outros fatores sempre lhe foram apostos na superfície, mas ignorados na necessária verticalidade, como a fundamental questão do valorizado uso de mão-de-obra dos escravizados em uma economia mercantil escravista apresentada, paradoxalmente, como de subsistência ou, até mesmo, como camponesa. Paradoxos estimuladores da perspicácia compreensiva, negligenciados por muitos e reproduzido por outros tantos.

Crescendo em silêncio, agora em livro, sempre foi texto foco de luz sobre essas controversas interpretações; reflexão crítica e ousada, corajosa no sentido de apontar o foco para elementos fundamentais formadores do repertório multifatorial da complexidade da economia mineira dos séculos XVIII e XIX.Em função disso, estimula, há tempos, controvérsias.

A historiografia sobre Minas Gerais a partir dos anos 1980 tem apresentado visões enriquecidas do processo, em muitos trabalhos que, apegados a percursos de investigação empírica e à criatividade nas opções de análises, propõem novas percepções e maior aderência à realidade. Ambos, resquícios documentais e problematizações inovadoras, possibilitaram tal direção compreensiva. Diria, no entanto, que a coragem libertadora desses trabalhos foi sedimentada em Growing in silence, de Robert Martins.

A utilização das fontes censitárias e as cartorárias explicam em parte o enriquecimento da leitura de um passado complexo. Elas possibilitaram ver um mercado pujante em nível interregional, uma vigorosa manufatura amalgamando grande diversidade de ofícios artesanais, uma riqueza acumulada por famílias e por redes de clientelas diversas, uma dinâmica de envolvimentos e de investimentos em construção civil, uma economia rural forte e demandada por população crescente. Mas é a problematização criativa do objeto estimulada por essas fontes que enseja a necessária complexização de evidências.

De uma "visão indiferenciada de uma decadência inexorável e monolítica, sem atentar para as infinitas diversificações locais" como criticava Maria Yedda Linhares, em 1978, no Seminário sobre a cultura mineira 
no período colonial, à citada diversificação interpretativa da dinâmica da economia de Minas colonial e provincial a partir dos anos 1980, muita riqueza compreensiva se produziu, diria estimulada por esse chamamento (mesmo que Martins o veja apenas como uma fala que provocou apenas um "frisson passageiro") e motivada pela "tese seminal" de Roberto Martins. A riqueza da discussão nessa década de novas e importantes produções historiográficas teve balanço perspicaz produzida por Douglas Cole Libby, já em $1988^{1}$.

A minha leitura de Crescendo em Silêncio, agora não de forma fragmentária em artigos e textos esparsos como aconteceu nos idos dos anos de 1990, época de meu Mestrado, aquilata de forma mais consistente toda a força da tese de Martins. Minha leitura inicial de "Slavery in a Nonexport Economy", escrita em conjunto com Amílcar Martins Filho (a famosa "proposta dos irmãos Martins"), síntese da tese agora publicada, encaminhou-me a maior gama de possibilidades de apreensão daquilo que eu próprio ia encontrando nos arquivos. Em tentativa sintetizadora, penso sua tese como construída a partir de rigoroso diálogo historiográfico - feito em perspectiva de um economista com sensibilidade revisionista acurada - com problema histórico bem delineado: a ideia central de que o espaço histórico da província de Minas não atendia ao modelo que se propugnava para as economias escravistas. Era, predominantemente uma economia não exportadora, com absorção da mão-de-obra escravizada em uma gama muito grande de atividades para além da ação no eito sob o olhar fiscal e repressor da estrutura senhorial.

A apresentação da "incrível economia escravista de Minas Gerais no século XIX” agora editada em livro em suas duas partes, nos apresenta

1 Esta será a única nota de rodapé referencial do texto, almejando o papel que cabe a uma resenha acadêmica, o de comentar o livro para, com sua crítica, estimular novas leituras. Referencio Linhares e Libby para indicar caminhos de investigação historiográfica aos leitores. As referências de produções mais recentes estão no post scriptum de Roberto B. Martins. LINHARES, Maria Yedda Leite. "O Brasil no século XVIII e a Idade do Ouro: a propósito da problemática da decadência”. In: Seminário sobre a Cultura Mineira no Período Colonial. Belo Horizonte: Conselho Estadual de Cultura de Minas Gerais, 1979; LIBBY, Douglas Cole. "Historiografia e a formação social escravista mineira". In: Acervo, v. 3, n. 1, p. 7-20. Rio de Janeiro, 1988. A citação ao "frisson passageiro" do chamamento de Maria Yedda Linhares está na segunda parte do livro objeto desta resenha, às páginas 409-410, nota 15. A epígrafe inspira-se em ATLAN, Henri. Entre o cristal e a fumaça. Ensaio sobre a organização do ser vivo. Rio de Janeiro: Jorge Zahar Editor, 1992, p. 9-10. 
a tese inicial do autor escrita em 1979 e defendida em 1980 .... e "Quarenta anos depois", uma Parte II que enfrenta as críticas, interpõe o que o autor considera seus erros ("pecados veniais e mortais"), justificando-os e fazendo franca autocrítica, bem como, e principalmente, uma reflexão autoral primorosa a contrapor sua compreensão da economia escravista mineira, feita há 40 anos, frente a uma historiografia sobre a economia mineira, brasileira e mundial produzida ao final do século XX e primeiros anos do XXI.

"Incrível" é adjetivo do subtítulo da obra, escolhido por Martins, a denotar a sua compreensão da economia oitocentista mineira. Também o título é bem pensado, incorrendo na mesma característica imposta por ele a Robert Slenes, "dotado de grande talento literário" para construir um "título esperto" como "meio caminho andado para um best seller". É por pensá-la incrível que Roberto Martins esmiúça a economia mineira tentando diferenciá-la dos modelos explicativos dos escravismos modernos então vigentes. Incrível porque extraordinária, nada banal, inacreditável, inimaginável às vezes, mas histórica e, dessa forma, crível. A incrível crível, se podemos brincar com a liberdade literária de que tanto gosta o autor, com seus porcos metafóricos - com corpos e rabos - e suas pérolas (diamantes) do versículo de São Mateus e do jogo de palavras de Slenes. Crível, porque em sua surpreendente e imprevisível construção histórica, é uma economia acreditável, aceitável, plausível provável, verossímil.

A primeira parte, a despeito de muito conhecida e quase dispensar comentários traz informações preciosas e uma discussão metodológica que nos clareia o percurso compreensivo, justifica rigorosamente a tese e comprova a capacidade do investigador crítico, atento aos conceitos e proposições e de uma perspicácia fundamental. Essa capacidade perspicaz é clara nos fundamentos econômicos e criativa nos sociohistóricos. Os setores minerador e cafeeiro são escolhidos como cenário de uma economia, para se entender o trabalho do homem escravizado e a ação gestora de companhias e de senhores sobre ele. O tráfico e a população de trabalhadores compulsórios, as características da manumissão e o apego dessa economia ao escravismo eixam a percepção das suas transformações estruturais. Tudo em ótica diagnóstica, quase de dissecação, de lapidação dessas estruturas cristalizadas. 
A segunda parte nos apresenta um autor que ao longo do tempo elaborou críticas, dialogou intelectualmente com os pares, descobriu novos documentos, valorizou novos autores, conheceu a amplitude da produção historiográfica sobre Minas Gerais nos últimos 40 anos e reviu sua tese. É um post scriptum onde a sinceridade agride estimulantemente o leitor para que ele participe do diálogo, conduzido pelo propositor-autor. Roberto Martins tem esse dom, tanto no discurso oral quanto no escrito, de provocar sinceridades. No escrito após tempos, exerce franqueza e humildade e, de outro modo reafirma e reconfigura propostas elaboradas há 40 anos. Nesse exercício possibilita ao leitor uma reflexão que ultrapassa o seu exercício de autor e os estimula a pensar sobre os próprios achados e reflexões. Talvez nesta parte, resida um dos valores essenciais da edição de Crescendo em Silêncio: ela rearticula o impacto da tese de 1980, apresentada na íntegra na primeira parte.

As principais críticas recebidas nos inúmeros diálogos do lapso temporal de 40 anos são enfrentadas sem meias palavras. Aceita-as em parte, reconhece excessos, revigora achados, reconfigura interpretações e, no fundo, rejuvenesce sua tese. $O$ espaço oitocentista, não mais invisível e, agora, revitalizado com a edição de Crescendo em silêncio, exige agora mais de seus intérpretes quanto ao uso da terra, ao suposto "ensimesmamento" de sua economia, ao trânsito migratório de populações escravizadas, aos deslocamentos espaciais das atividades agrárias e manufatureiras, aos caminhos de um desenvolvimento diverso, às redes clientelares de câmbios de poder etc. As críticas mais fundamentais à tese de Roberto Martins - a importância do mercado interno das Minas e relação deste com os outros mercados provinciais, a natureza do crescimento da população de escravizados, a própria natureza de seu modelo não-exportador - precisam de vigor que dialogue novamente com o seu post scriptum. Roberto Martins pede tréplicas!

Na perspectiva da longa duração muitas questões podem ser repensadas a partir da leitura de Crescendo em Silêncio. Duas delas me são caras: é preciso dar aderência real à ideia de inversão econômica ou de inflexão econômica para uma economia agrária no final do século XVIII e século XIX, a partir da decadência da produção minerária. A segunda é a própria percepção de que o setor minerador, na história de Minas, nunca deixou de ser fundamental. Aí, é preciso aprofundar a discussão da ideia 
de "decadência", pensando o mercado colonial e o mercado provincial. $\mathrm{Na}$ busca compreensiva das duas questões é necessário ter como premissa que a ordem econômica e a ordem social não estão apartadas e demandam compreensão complexa.

Economista-Historiador, Roberto Martins sabe transitar entre campos e tem estofo instrumental para proposta revisionista e inovadora. Não se contenta nem com uma e nem outra: insere seu trabalho no campo da historiografia e da economia. Busca diálogos dificeis, embora urgentes com os dois campos acadêmicos. Diria que faz isso há 40 anos. Não lhes bastam as teorias e o modelos explicativos porque parece ser motivado pelas suas lacunas, suas frestas. Isso o obriga ao diálogo e à propostas francas de bons embates. Provoca-os com certo atrevimento de quem conhece e não se satisfaz com o que apreende. Exige de si e daqueles com que busca dialogar a clareza das coisas descobertas e explicitadas. Neste sentido, facilita o exercício nem sempre fácil da transdisciplinaridade. É bom ler a íntegra de Crescendo em silêncio. Melhor é usar o texto para motivar nossos próprios questionamentos aos modelos explicativos não revigorados. O texto de Roberto Martins fez e faz o cristal virar fumaça.

Belo Horizonte, novembro de 2019. 